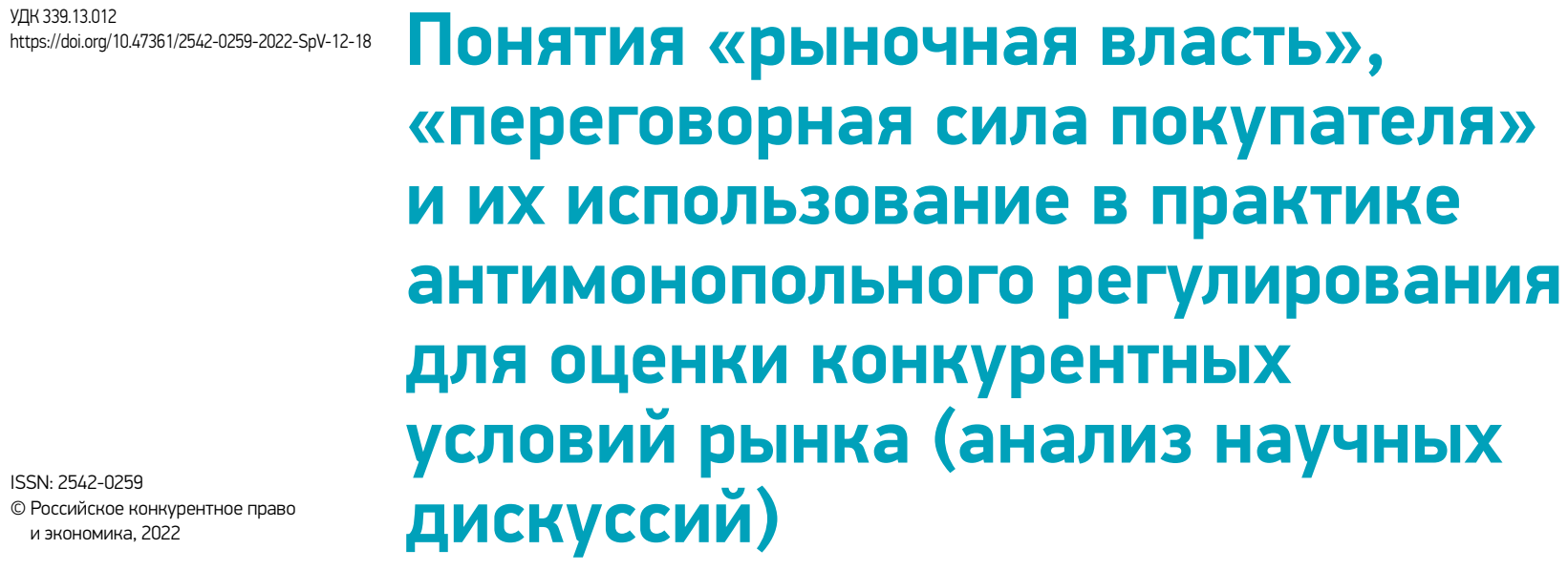

Князева И.В.*, Заикин Н.Н.,

Сибирский институт управления - филиал РАНХиГС, 630102, Россия, г. Новосибирск, ул. Нижегородская, д. 6

\begin{abstract}
Аннотация
Выполнен анализ научных публикаций, посвященных понятиям «рыночная власть» и «переговорная сила покупателя». Рассмотрена эволюция мнений о конкурентных условиях рынка, формах межфирменных взаимодействий и антиконкурентного поведения. Изучены позиции исследователей относительно влияния рыночной (переговорной) власти покупателей на общественное благосостояние и необходимости использования данных категорий в конкурентном праве и практике антимонопольного регулирования.
\end{abstract}

Ключевые слова: рыночная власть покупателя, переговорная сила покупателя, уравновешивающая сила, конкурентные условия рынка, монопсония, антимонопольное регулирование.

Для цитирования: Князева И.В., Заикин Н.Н. Понятия «рыночная власть», «переговорная сила покупателя» и их использование в практике антимонопольного регулирования для оценки конкурентных условий рынка (анализ научных дискуссий) // Российское конкурентное право и экономика. 2022. SpV. C. 12-18,

https://doi.org/10.47361/2542-0259-2022-SpV-12-18

Авторы заявляют об отсутствии конфликта интересов. 


\section{The Concepts of "Market Power", "Negotiating Power of the Buyer" and their Use in the Practice of Antimonopoly Regulation to Assess the Competitive Conditions of the Market (Analysis of Scientific Discussions)}

Irina V. Knyazeva*, Nikolay N. Zaikin,

Siberian Institute of Management — branch of RANEPA,

Nizhegorodskaya str., 6 , Novosibirsk, 630102, Russia

\begin{abstract}
The analysis of scientific publications devoted to the concepts of "market power" and "negotiating power of the buyer" is carried out. The evolution of opinions about competitive market conditions, forms of intercompany interactions and anticompetitive behavior is considered. The positions of researchers regarding the influence of the market (negotiating) power of buyers on public welfare and the need to use these categories in competition law and antimonopoly regulation have been studied.
\end{abstract}

Keywords: buyer's market power, buyer's bargaining power, balancing force, competitive market conditions, monopsony, antimonopoly regulation.

For citation: Knyazeva I.V., Zaikin N.N. The concepts of "market power", "negotiating power of the buyer" and their use in the practice of antimonopoly regulation to assess the competitive conditions of the market (analysis of scientific discussions) // Russian Competition Law and Economy. 2022;(SpV):12-18 (In Russ.), https://doi.org/10.47361/2542-0259-2022-SpV-12-18

The authors declare no conflict of interest.

\section{Введение}

опросы рыночной власти доминирующего на рынке продавца или покупателя являются предметом многих научных исследований, отражены в законодательстве многих стран, в антимонопольной правоприменительной (в том числе судебной) практике. В меньшей степени исследованы вопросы влияния на рынок продавцов или покупателей, не обладающих структурным доминированием, но имеющих при взаимодействии на рынке потенциальную рыночную власть и переговорную силу.

Важно отметить, что изучение вопросов одностороннего поведения доминирующих субъектов монополистического или монопсонического типа на отраслевых рынках активизировалось после опубликования работы Э. Мейсона по парадигме «структураповедение-результат» [1]. Несмотря на акцент, сделанный на поведении монополистов, Э. Мэйсон утверждал, что контроль за рынком может осуществлять как продавец, так и покупатель, имея власть не только за счет объема продаж и активов, но и за счет практики продаж: крупным предприятиям доступны более совершенный маркетинг и лучшая реклама по сравнению с мелкими фирмами [1, с. 62-63].

Вместе с тем исследовательское поле Э. Мэйсона и многих ученых середины прошлого века долго не расширялось рассмотрением особенностей формирования и проявления рыночной власти или переговорной силы, в том числе через инструменты маркетинга, при отсутствии структурного приоритета. Ситуация стала быстро меняться, когда большинство отраслевых рынков трансформировалось из рынков продавцов в рынки покупателей, достигнув переломной точки с появлением крупных ретейлеров в конце 
прошлого столетия. Во второй половине прошлого века появились публикации зарубежных ученых (Д. Стиглер, Л. Флетчер, С. Чэ и П. Хэдхьюс, Ч. Линдблом, М. Портер, Ж. Тироль, Ф. Шерер и Д. Росс, Д. Миллс, Р. Нолл, Ч. Холт, Каприс и Рэй, Индерст и Шаффер, и др.) [2-13], расширяющие трактование рыночной власти и переговорной силы покупателей.

Проблемы структурно-критериальных характеристик, поведенческих установок и регулирования антиконкурентных практик субъектов, обладающих рыночной властью покупателя, стали обретать большую популярность в зарубежных теоретических исследованиях экономистов и юристов, а также в юридической практике. За последние три года только в отечественной научной литературе вышло несколько публикаций по данной теме - экономистов А.Е. Шаститко, Н.С. Павловой, А.Н. Морозова, В.В. Радаева, С.В. Ореховой, Е.В. Кислицына, юристов А.О. Закатаева, В.Ф. Попондопуло, Д.А. Петрова [14-20].

Полагаем, что по данной теме в ближайшее время в отечественном научном дискурсе появится много новых мнений о содержании категорий «переговорная сила» и «рыночная власть покупателя», целесообразности их нормативного правового закрепления и подходах K «демаркации» оценок поведения покупателей для целей антимонопольного правоприменения. В предлагаемой статье рассмотрим наиболее общие вопросы, характеризующие полемическую силу и важность исследовательского мейнстрима категорий «переговорная сила» и «рыночная власть покупателя».

\section{О содержании понятий «переговорная сила» и «рыночная власть покупателя»}

Одним из первых в экономической теории модель манипулирования переговорной силой покупателя сформулировал Л. Флетчер, отмечавший, что ее характер предусматривает комплекс действий, с помощью которых компания пытается установить более выгодные цены, чем те, которые преобладали ранее [3].

В модели переговоров С. Чэ и П. Хэдхьюса альянс покупателей делегирует переговоры кому-то из идентичных участников с общим пониманием того, что прибыль от переговоров распределяется поровну между всеми членами альянса [4]. И хотя альянсы могут иметь формальное закрепление, например, на основе слияния компаний или объединения в союз, фактически они могут регулироваться и неформальными договоренностями, например, путем делегирования переговорщика, который представляет интересы покупателей, не имея на то юридических прав.

В модели Д. Миллса рассматривается использование рыночной власти крупным покупателем, который появляется в результате роста, слияния или коллективной покупки [9]. Миллс подчеркивает, что крупным покупате- лем может быть кооперативная ассоциация небольших покупателей, так же, как групповая закупочная организация или даже закупочный картель.

Г. Мэнкью дает следующее определение рыночной власти: это способность одиночного хозяйствующего субъекта (или малой группы акторов) существенно влиять на рыночные цены [21, с. 12].

Со второй половины XX в. исследователи начали формулировать дефиниции и модели переговорной силы на товарных рынках.

Л. Флетчер дал следующее определение понятия переговорной силы: «По аналогии термин (bargaining power) может быть определен как право осуществлять принуждение, навыки ведения переговоров, монопольная власть, контроль поставок, или, как часто утверждают, “другой фактор” при определении цены» [3, с. 2].

На то, что при определенных условиях покупатели могут обладать сильным влиянием на продавца или производителя, одним из первых обратил внимание М. Портер [6]. К этим условиям относятся: стандартизированность товара, приобретение покупателем товара для промежуточного потребления с затратой на него значительной части своего бюджета, отсутствие стабильного потребления товара (может сформировать у покупателя недозагрузку мощностей или угрозу собственному производству товара) и др. Большинство источников покупательской силы могут проявляться как на рынке продаж домохозяйствам, так и на рынке продаж компаниям.

Исследование эластичности спроса и цепочки формирования ценностей позволило М. Портеру определить важный элемент переговорного доминирования в экономической модели, когда покупатели в статусе розничных торговцев могут получить значительную переговорную власть над поставщиками-производителями, если способны повлиять на решения их потребителей о покупке'.

Важно отметить, что исследования М. Портера позволили выделить и систематизировать основные положения конкурентного многообразия, выделив и описав модель пяти конкурентных сил на отраслевом рынке: переговорная сила покупателей, переговорная сила поставщиков, угроза появления новых участников, угроза появления товаров-заменителей, борьба за позицию на рынке.

Канадский исследователь Б. Раффл замечает, что в научной литературе цитируются два основных источника власти покупателя: размер покупателя и интенсивность конкуренции продавцов. По его мнению, в условиях рынка основным источником власти покупателя являются угрозы покупки товара у конкурентов.

\footnotetext{
Впервые Майкл Портер описал эту ситуацию в статье «Поведение потребителей, сила продавцов и рыночная эффективность в отрасли производства потребительских товаров». - Прим. авт.
} 
Альтернативой несогласия с ценовыми требованиями покупателя становится потеря крупной продажи более сговорчивому конкуренту [22, с. 108-137].

Важным термином, встречающимся в научной литературе, является категория «уравновешивающая сила», предложенная в исследованиях профессора Гарвардского университета Джона Гелбрейта [23].

В своих работах он подчеркивает, что уравновешивающая сила есть синоним переговорной силы, так как методы влияния переговорной силы фактически совпадают с методами действия уравновешивающей силы давление массового покупателя в лице кооперативов на цену товара. Уравновешивающая сила - это способность нейтрализовать позицию другой рыночной власти продавца. Рыночная власть одной из сторон должна быть уравновешена другой силой, это путь к большей социальной стабильности и экономической эффективности. Однако у этой позиции нашлось много критиков среди экономистов [24].

Российские исследователи А.Н. Морозов и Н.С. Павлова считают, что рыночная власть и переговорная сила - разные понятия и разделить их бывает трудно, поскольку в большинстве случаев они сопутствуют друг другу [14].

Попытка разделения понятий рыночной власти, переговорной власти и уравновешивающей силы была предпринята в статье «Переговорная сила и рыночная власть: варианты соотношения и выводы для политики» А.Е. Шаститко и Н.С. Павловой. Авторы делают несколько важных допущений относительно аналитической рамки понятийного аппарата. По их мнению, «переговорная сила рассматривается как относительная категория с помощью анализа механизма цен. Эталонный или теоретический результат рассмотрен в терминах равновесия, тогда как фактический или экспериментальный результат есть отсутствие равновесия по отношению к эталону» [15, c. 41].

Переговорная сила, по мнению названных авторов, не сводится лишь к наличию рыночной власти, которая является только одним из источников такой силы. Переговорная сила - это также и конкретные институты обмена («правила игры, включая обеспечивающие их соблюдение механизмы»), стратегическое поведение отдельных игроков, «в отличие от рыночной власти, обусловленной привычными характеристиками структуры рынка» $[15$, с. 41$]$.

\section{Влияние рыночной власти и переговорной силы покупателя на конкурентные условия рынка и практику антимонопольного регулирования}

В исследовании В.В. Радаева отмечается, что в системе экономического взаимодействия «поставщики-ретейл» на рынке российского ретейла рыночная власть перешла от поставщиков, господствовавших в 1990-е гг., к ры- ночным продавцам в начале нынешнего столетия [16]. Розничные продавцы используют власть для требований гарантированных доходов от розничной сети, бонусных обязательств от поставщика, предоставления поставщиками дополнительных услуг и др.

В исследованиях Организации экономического сотрудничества и развития (ОЭСР) власть покупателя описывается как монопсоническая и переговорная [25]. При этом ключевое отличие двух явлений состоит в том, что использование монопсонической власти приводит к снижению цен ниже конкурентного уровня, тогда как использование переговорной силы может уравновесить рыночную власть продавцов и подтолкнуть цены к конкурентному уровню. Проблема данного определения состоит в том, что экономисты не пришли к полному консенсусу в вопросе, какой уровень цены можно считать конкурентным.

Безусловно, в рыночном обмене существуют потенциальная и реальная силы воздействия сторон друг на друга с целью формирования взаимовыгодных условий функционирования. В рыночном обмене можно рассмотреть переговорную силу как, с одной стороны, потенциал влияния на оппонента, а с другой стороны, как реальный инструмент влияния, проявляющийся в переговорах. Проблема в том, что про рыночную власть можно сказать то же самое.

По мнению Д.А. Петрова, «современное понимание власти покупателя учитывает не только власть в масштабе всего рынка, но и наличие переговорной силы на уровне двусторонних отношений» [20].

В.Ф. Попондопуло отмечает, что «исследование темы рыночной власти предполагает изучение понятия "экономический интерес", поиск ответов на вопросы о механизмах обеспечения баланса интересов между продавцом и покупателем» [19].

В исследованиях А.О. Закатаева, изучавшего зарубежный опыт юридического закрепления и практики правоприменения рыночной и переговорной власти покупателя в условиях современных экономико-правовых реалий, отмечается, что «представление о власти покупателя (монопсонии) как зеркальном отражении власти продавца (монополии) можно считать устаревшим» [18]. Автор отмечает, что в начале 2000-х гг. большинство юрисдикций обратили внимание на регулирование власти покупателя в связи с усилением концентрации на рынке продуктового ретейла.

Активная научная дискуссия в зарубежных странах по вопросам рыночной власти покупателя и переговорной силы, реализуемой нередко благодаря маркетинговым инструментам, оказала влияние на нормативное закрепление и формирование на практике правовых принципов в сфере антимонопольного регулирования и в области конкурентного права. Следует отметить, что возрастание интереса к теме регулирования переговорной власти покупателей в большинстве юрисдикций 
было связано с исследованием потенциально антиконкурентных практик торговых сетей (супермаркетов). Однако ни в одной из юрисдикций возможность регулирования власти покупателей не ограничивается исключительно сектором ретейла, и правовые подходы, применяемые к торговым сетям, потенциально применимы к покупателям на любом рынке вне зависимости от целей, с которыми приобретается товар (перепродажа, переработка).

Во всех юрисдикциях в той или иной форме выделяются два вида власти покупателя: рыночная и переговорная. Нормативные акты и правоприменение постепенно совершенствуются таким образом, чтобы отличать рыночную власть (доминирующее положение) и переговорную силу (относительное доминирующее положение), которая возникает в двусторонних отношениях участников рынка.

Взаимоотношения между доминирующим поставщиком и неопределенным кругом покупателей, обладающих той или иной формой власти покупателя, наиболее полно описываются в юрисдикциях понятием «уравновешивающая сила». При оценке эффекта уравновешивающей силы важную роль играет возможность распространения эффекта на неопределенный круг покупателей.

\section{Выводы}

Анализ изученных научных публикаций позволяет сделать следующие выводы.

На рыночную власть и переговорную силу покупателей влияют количество продавцов и покупателей на рынке, эластичность предложения и асимметрия информации. Чем меньше покупателей на рынке и больше продавцов, а также чем менее значима эластичность товара, тем выше власть покупателя монопсонического типа. Высокая степень осведомленности покупателя о рынке и контрагентах, их условиях функционирования и формирования политики продвижения стимулирует его к переговорному процессу, торгу и давлению на цену.

В научных дискуссиях присутствует мнение, что важно не столько количество продавцов, сколько интенсивность конкуренции за покупателя. Наличие у покупателя и продавца долгосрочных хозяйственных связей стимулирует покупателя вести себя более активно в решении задач по снижению цен. Покупатель, обладающий знанием об издержках на их удержание, будет использовать давление в переговорном процессе с учетом возможности и эффективности своих переключений между продавцами.

Влияние покупателей на цену может осуществляться за счет «шантажа» с последующей угрозой перехода к конкуренту, требований лояльности, ссылки на более низкую цену и лучшие условия поставки у конкурента. Покупатели могут влиять за счет рыночной власти или переговорной силы на цену и условия поставки товара, навязывать дополнительные требования (например, отсрочку оплаты товаров), устанавливать барьеры для входа на рынок («входной билет»). Благосостояние продавца в любом случае уменьшается, но последствия для рынка могут быть различные.

При оценке состояния конкурентной среды и системы межфирменных взаимодействий важен как объем оборота, так и статус покупателя. Чем крупнее покупатель, тем сильнее его рыночная власть. По нашему мнению, объем оборота — это не единственный фактор рыночной власти. Наличие отраслевого, регионального или национального статуса субъекта, имеющего силу бюджетообразующего предприятия на территории, как, например, градообразующего предприятия в моногородах, может оказывать влияние на формирование переговорной позиции.

Покупатели могут объединяться в альянсы, ассоциации и союзы, их деятельность может координироваться и носить лоббистский характер, в том числе при формировании институциональных привилегий и приоритетов. Они могут осуществлять договорные закупки с целью снижения цены, если эти объединения не будут носить антиконкурентный характер.

Ситуация на нижестоящем рынке покупателя, где он является продавцом, прямо зависит от рыночной власти и переговорной силы его покупателя: чем сильнее давление спроса на нижестоящем рынке - объем спроса, цены, структура, - тем выше власть и сила покупателя на вышестоящем рынке. Принципиально важно переносить выгоды приобретателя первого уровня на цепочку нижестоящих потребителей. При отсутствии перенесенного эффекта промежуточных потребителей на нижестоящие рынки можно говорить о наличии переговорной силы, нарушающей конкурентные условия рынка.

Издержки продавца на первичном рынке имеют существенное значение для общественного благосостояния и два направления потенциальных последствий как для конечных потребителей, так и для рынка в целом.

Экономическим способом определения переговорной силы может стать анализ отклонений цены продаж от конкурентной цены или анализ суммы и процента предоставляемых продавцом скидок. В случае если конкурентную цену нельзя по тем или иным причинам смоделировать, в качестве данной цены может выступать цена на аналогичный товар на сопоставимых рынках других регионов или стран.

При рассмотрении ситуации ценовых различий важным исследовательским инструментом является сопоставление издержек и преимуществ от рыночной власти или переговорной силы для вышестоящего рынка (наличие или отсутствие уравновешивающей силы), нижестоящего рынка и общественного благосостояния (наличие или отсутствие издержек или выгод для общественного благосостояния от деятельности покупателя). 
Таким образом, имея близкие характеристики и поведенческую природу, реализация рыночной власти и переговорной силы может иметь не только разные содержательные, тактические и стратегические проявления, но и различные последствия для конкурентных отношений на рынке как в краткосрочном, так и в долгосрочном периоде и, соответственно, представлять потенциальную угрозу для продавцов, рынков и экономики страны. Важно, чтобы результаты переговорной силы имели позитивные последствия для покупателей, которые не обладают рыночной властью или переговорной силой.

Ключевым индикатором, отражающим отрицательное проявление результатов переговорной силы, является отсутствие перенесенного эффекта на нижестоящие рынки (потребителей) соизмеримой части выигрыша, полученного промежуточными потребителями (дистрибьютор, торговая сеть и др.) в результате переговорного давления на продавца как обладающего доминирующей позицией, так и при отсутствии таковой. При такой рыночной ситуации можно говорить о наличии или злоупотреблении переговорной силой, нарушающей конкурентные паритеты рынка и приоритеты общественного благосостояния, что предполагает включение регуляторных инструментов рынка со стороны государства, в том числе закрепление категорий «рыночная власть» и «переговорная сила» в системе норм антимонопольного регулирования и конкурентного права, а также комплексе методических документов, отражающих исследование конкурентной среды на товарных рынках.

\section{Литература [References]}

1. Mason Edward S. Price and Production Policies of Large-Scale Enterprise // The American Economic Review. Vol. 29. № 1. American Economic Association, 1939. P. 61-74.

2. Stigler George J. A theory of oligopoly // Journal of Political Economy. Vol. 72, No. 1 (Feb., 1964), P. 44-61.

3. Center for Agricultural and Economic Adjustment, lowa State University; Fletcher, Lehman B.; Paulsen, Arnold; Kaldor, Donald R.; Stucky, W. G.; Talbot, Ross B.; Davey, Harold W.; Hines, Harold H.; Kolmer, Lee R.; Kutish, Francis A.; Strain, J. R.; Scott, J. T.; Rackham, T. S.; and Nordin, J.A., "Bargaining power in agriculture” (1961). CARD Reports. 14.

4. Heidhues Paul \& Chae Suchan. (2004). Buyers' Alliances for Bargaining Power. Journal of Economics \& Management Strategy. 13. P. 731-754.

DOI: $10.2139 /$ ssrn.497062

5. Lindblom C.E. Bargaining Power in Price and Wage Determination // Quarterly Journal of Economics, Vol. LXII, No. 3 (May 1948). P. 396-417.

6. Майкл Портер. Конкурентная стратегия: Методика анализа отраслей и конкурентов / Пер. с англ.
М.: Альпина Бизнес Букс, 2005. 454 с. [Michael E. Porter. Competitive strategy: Techniques for analyzing industries and competitors / Translation from English. M.: Alpina Business Books. 2005. 454 p.]

7. Тироль Ж. Рынки и рыночная власть: Теория организации промышленности / Пер. с англ. СПб.: Экономическая школа. 1996. 794 с. [Jean Tirole. The theory of industrial organization / Translation from English. SPb.: Economic school. 1996. 794 p.]

8. Шерер Ф., Росс Д. Структура отраслевых рынков: Уч. / Пер. с англ. М.: Инфра-М. 1997. 698 с. [Scherer F., Ross D. Industrial market structure and economic performance / Translation from English. M.: Infra-M. 1997. 698 p.]

9. Mills David. (2010). Buyer Power and Industry Structure. Review of Industrial Organization. 36. P. 213-225. DOI: 10.2307/41799463

10. Holt C.A. Industrial organization: A survey of laboratory research // Handb. Exp. Econ. Princeton, NJ: Princeton University Press, 1993.

11. Noll Roger. (2005). Buyer Power and Economic Policy. Antitrust Law Journal-ANTITRUST LAW J. 72. P. 589-624.

12. Caprice Stéphane \& Rey Patrick. (2012). Buyer Power from Joint Listing Decision. The Economic Journal. 125. P. 1677-1704. DOI: 10.1111/ecoj.12241

13. Inderst R. \& Shaffer G. Buyer power in Merger control. In W. D. Collins (Ed.) // Issues in competition law and policy. Chicago: American Bar Association, 2008. Vol. II. P. 1611-1635.

14. Морозов А., Павлова Н. Переговорная сила и рыночная власть: подходы к разделению для целей антимонопольной политики (март 1, 2019)

URL: https://ssrn.com/abstract=3347609..

http://dx.doi.org/10.2139/ssrn.3347609 (Дата обращения: 06.11.2021). [Morozov A. and Pavlova N. Bargaining Power and Market Power: Approaches to Separation for the Purposes of Antitrust Policy (March 1, 2019). (In Russ.). Available at SSRN:

https://ssrn.com/abstract=3347609 or http://dx.doi.org/10.2139/ssrn.3347609]

15. Шаститко А.Е., Павлова Н.С. Переговорная сила и рыночная власть: варианты соотношения и выводы для политики // Журнал Новой экономической ассоциации. 2017. № 2 (34). С. 39-58.

https://doi.org/10.31737/2221-2264-2017-34-2-2 [Shastitko A.Y., Pavlova N.S. Bargaining power and market power: comparison and policy implications studies of the russian economy // Journal of the New Economic Association. 2017;(2(34)):39-58 (In Russ.) https://doi.org/10.31737/2221-2264-2017-34-2-2]

16. Радаев В.В. Рыночная власть и рыночный обмен: отношения розничных сетей с поставщиками // Российский журнал менеджмента. 2009. Т. 7. № 2. С. 3-30. [Radaev V.V. Market power and market exchange: 
relations of retail chains with suppliers // Russian Management Journal. 2009;7(2):3-30 (In Russ.)]

17. Орехова С.В., Кислицын Е.В. Уровень властной асимметрии и экономический рост промышленных отраслевых рынков: теоретический и эмпирический анализ // Известия УРГЭУ. 2018. Т. 19. № 4. С. 121-135. https://doi.org/10.29141/2073-1019-2018-19-4-9 [Orekhova S.V., Kislitsyn Ye.V. Power asymmetry and economic growth of industrial markets: theoretical and empirical analysis // Journal Of The Ural State University Of Economics. 2018;19(4):121-135 (In Russ.) https://doi.org/10.29141/2073-1019-2018-19-4-9]

18. Закатаев А.О. Антимонопольное регулирование власти покупателя в зарубежных юрисдикциях на примере правопорядка США // Конкурентное право. 2021. № 4. C. 10-13.

https://doi.org/10.18572/2225-8302-2021-4-10-13 [Zakataev A.O. The antimonopoly regulation of the buyer's power in foreign jurisdictions on the example of the U.S. law and order // Competition Law. 2021;(4):1013 (In Russ.)

https://doi.org/10.18572/2225-8302-2021-4-10-13]

19. Попондопуло В.Ф. Рыночная власть производителей и потребителей товаров, формы ее проявления и законодательное регулирование // Конкурентное право. 2021. № 4. С. 2-9.

https://doi.org/10.18572/2225-8302-2021-4-2-9 [Popondopulo V.F. The market power of manufacturers and consumers of goods, its manifestation forms and legislative regulation // Competition Law. 2021;(4):2-9 (In Russ.) https://doi.org/10.18572/2225-8302-2021-4-2-9]

20. Петров Д.А. Рыночная власть и переговорная сила как категории антимонопольного регулирования // Конкурентное право. 2021. № 1. С. 4-7. https://doi.org/10.18572/2225-8302-2021-1-4-7

[Petrov D.A. The market power and the bargaining power as antimonopoly regulation categories // Competition Law. 2021;(4):4-7 (In Russ.)

https://doi.org/10.18572/2225-8302-2021-1-4-7]

21. Mankiw N.G. Principles of Microeconomics. SouthWestern College Pub. 2008. 5th Edition (January 1, 2008). $519 p$.

22. Ruffle B. When Do Large Buyers Pay Less? Experimental Evidence // The Journal of Industrial Economics. 2013. Vol. 61. No. 1. P. 108-137.

23. Galbraith J.K. American Capitalism. The Concept of Countervailing Power / Boston: "Houghton Mifflin Co.", 1952.

24. Galbraith John Kenneth. Countervailing Power. The American Economic Review, 1954. Vol. 44. № 2. P. 1-6.

25. OECD (2008). Monopsony and Buyer Power. Policy Roundtables. DAF/COMP(2008)38.

URL: https://www.oecd.org/daf/competition/44445750. pdf (Дата обращения / Accessed: 06.11.2021).

\section{Сведения об авторах}

Князева Ирина Владимировна: доктор экономических наук, профессор, РАНХиГС (Сибирский институт управления - филиал), профессор, руководитель Центра исследования конкуренции и экономики irknyazeva @yandex.ru

Заикин Николай Николаевич: кандидат экономических наук, доцент кафедры экономики инвестиций РАНХиГС (Сибирский институт управления — филиал) zaikin-nn@ranepa.ru
Статья поступила в редакцию: 30.12.2021

Одобрена после рецензирования: 24.01.2022

Принята к публикации: 24.01.2022

Дата публикации: 08.02.2022
The article was submitted: 30.12 .2021

Approved after reviewing: 24.01.2022

Accepted for publication: 24.01.2022

Date of publication: 08.02 .2022 